\title{
Transesterification of Nannochloropsis oculata microalga's oil to biodiesel using calcium methoxide catalyst
}

\begin{abstract}
Biodiesel is an environmental friendly liquid fuel similar to conventional diesel in combustion properties. It has received international attention in recent times, as that biodiesel is renewable, non-toxic and safe to store. In this study, high grade biodiesel was produced from microalgae (Nannochloropsis oculata) derived lipids via transesterification reaction with methanol in the presence of heterogeneous $\mathrm{Ca}(\mathrm{OCH} 3) 2$ (calcium methoxide) catalyst. The biodiesel was produced with high yield; $(92 \%)$ at $60{ }^{\circ} \mathrm{C}$ compared to the highest yield reported as $22 \%$ with the use of a $\mathrm{Mgï} \mathrm{Zr}$ catalyst. The product exhibited excellent performances. The catalyst was characterized by TG/DTA (thermogravimetric-differential thermal analyses), XRD (X-ray diffraction), BET (Brunauer $\ddot{i}$ Emmett $\ddot{i}$ Teller), FTIR (Fourier transform infrared), SEM-EDX (scanning electron microscopy-energy dispersive spectrometer) and TEM (transmission electron microscopy) analysis. The effect of different reaction parameters including reaction time, methanol/oil molar ratio and catalyst dosage on the yield of FAME (fatty acid methyl ester) was studied. Interestingly, the catalyst can be reused five times successively without affecting the biodiesel yield. Biodiesel produced from microalgae oil consists of high levels of polyunsaturated fatty acids, making it highly suitable as winter grade biodiesel.
\end{abstract}

Keyword: Biodiesel; Transesterification; Heterogeneous catalyst; Calcium methoxide; Nannochloropsis oculata 